\title{
LIFECYCLE VS ELEMENT COSTS: A NEW APPROACH TO OPTIMIZE THE POWER SUPPLY SYSTEM DESIGN IN RAILWAYS INFRASTRUCTURES
}

\author{
M. SOLER, J. LÓPEZ, J.M. MERA \& J. MAROTO \\ CITEF, Railway Technology Research Centre of the Universidad Politécnica de Madrid, Madrid, Spain.
}

\begin{abstract}
Electrification systems applied to railway systems have high complexity to achieve the optimum in several terms. These terms could be separated in energy supply and budget costs, such as direct and indirect costs, all of them derived from the implantation of the electrification system along the railway line. Starting from the experience in several projects carried out in CITEF (Railway Research Center in Technical University of Madrid), a new research way has grown up. The main goal has been an expert system, which is able to improve substantially the design process of power supply systems in railways, such as in AC as DC. Bearing in mind the specific constraints in terms of budget and electric standards, the expert system is able to determine a set of possible design scenarios. Each of them has the number, type and location for the main elements (catenary, substation, autotransformer, etc.). In this article a step forward is presented. This new step would apply a better way to choose between elements, hence taking into account the relationship between lifecycle versus element cost or losses avoided in the infrastructure. This has been applied to the main elements like traction substations, autotransformers, catenary and impact on maintenance and environmental zones. This new concept for evaluation has been integrated in the objective functions. These functions are the managers for the guidance of the optimization method, in this case genetic algorithm AMGA-II, in order to achieve the final Pareto Front. This Pareto Front contains the several possibilities which the designers must evaluate to accomplish their goals to power supply system.

Keywords: AMGA-II, life-cycle costs (LCC), maintenance and environmental zones, optimization, power supply design (PSD).
\end{abstract}

\section{INTRODUCTION}

The electrical system that supplies energy to the railway traction is a very complex system, which must achieve several important keys. Any power supply design (PSD) must include concepts such as electrical validation according to the standards, power demanded by trains of the operation plan, avoiding zones with high impact on environmental and maintenance zones, considering areas to connect with the general electric grid and finally budget of the project. The choice of the components and position through the line is a task which has been planned as a research way in several studies and works.

In CITEF a methodology has been developed during recent years. This methodology helps to find optimal solutions for the complex system explained before. The work developed by Soler et al. [1] is applied to the DC power supply using an expert system that helps in the choice about the PSD related to the railway traction. This expert system works with Hamlet Simulator [2] developed in CITEF and integrating a multi-objective genetic algorithm NSGAII [3]. The optimization algorithm from an initial configuration is able to converge to an optimum Pareto Front, which contains good proposals for the designer. The same research line

This paper is part of the proceedings of the 15th International Conference on Railway

Engineering Design and Operation (COMPRAIL)

www.witconferences.com 
was applied to electrification systems in AC in [4]. The validation process has been improved with the integration of more electrical terms in the genetic algorithm. The integration of the methodology with other algorithms like AMGA-II [5] is another new step.

Definitely, this research and developing line has been an effort to accomplish a methodology which was able to help properly the designers in their task of defining a complex system, adequate to electrical standards, adhering to a limited budget and positioning critical elements that avoid critical zones. But obviously this methodology can grow up in different ways and areas of the PSDs. In this article, the introduction of elements selection for the supply system taking into account the life-cycle costs (LCCs) and the energy losses versus element costs, and concepts attending to the environmental and maintenance influence, is presented.

In engineering projects the studies to install critical elements is very important to analyse the LCC. Hence if this study is focused on power supply systems in railways, in the article presented in Rondón [6], the authors were working in a manner to evaluate the LCC from studying the overload of the autotransformer they were analysing. Chester and Horvarth [7] discuss the problem to a high-speed system in California, where they are comparing with other means of transport and adding the calculated demand of ridership and the type of energy consumed. Finally they have integrated their conclusions to the related environmental impact. Another interesting study is given by Abbes et al. [8], where the authors could combine a multi-objective optimization system, studies of LCC, embodied energy and calculus of probability of energy losses in order to supply correctly the energy at homes. The highlight is how the settings are interacting internally and what exactly they have taken into account to reach the calculus of the parameters. Another use of the multiobjective algorithms in LCC joined with environmental impact is addressed by Cerri et al. [9], who worked with a theoretical model using the NSGA-II. In the same line but focusing on railway systems, Salim and Xiaoqiang [10] presented their work. Reading this method is interesting to know how the environmental costs are minimized in direct connection using the planned optimization model. The stops in stations and times of circulations are very important to achieve this goal.

Studying the possibilities to improve the LCC connected with other parameters belonging to railway systems is needed to obtain the way to weight these costs. In the document extracted from Baumgartner [11], a measure to weight properly is obtained. Performing this initial evaluation some optimization works more linked with the power supply in railway systems are integrated, such as the study of comparing energy losses among several systems [12]. Next research way highlighted has become a different combination topic of interest to apply. Chuang et al. [13] model the performance of the traction substations in a MRT (massive rail transit), and they are using an optimization algorithm (dynamic programming) and are taking into account the ridership demand through the line, load flow, energy losses and computational time derived, finally finding a method to adapt the PSD to the needs and calculated costs. Furthermore, Hinow and Mevissen [14] have applied a genetic algorithm, trying to achieve an optimum schedule for the substation maintenance. This handles a new method to reduce significantly the LCC.

Throughout this article, the theoretical model of performance of the genetic algorithm integrated in our methodology has been modified. The goal is to include in the objective functions the capacity to get a PSD, taking into account the LCC, joined with environmental and maintenance impact and finally, energy losses versus traction elements costs. The optimization has been carried out with the multi-objective genetic algorithm AMGA-II, final results of which allow the designers to choose between a set of good possible designs in terms of electrical, budget, LCC, energy losses and low impact on environmental and maintenance. 


\section{METHODOLOGY - INCLUDING LCC IN ENVIRONMENTAL-MAINTENANCE AND ENERGY LOSSES VERSUS INSTALLING ELEMENTS}

This topic is divided into two main parts. The first presents a short introduction about the later works related to the methodology, defining the most important features and skills to understand how it is working. Thereafter new introductions to include the LCC in some concepts that the methodology takes into account will be explained. It is important to mention that the new improvements have been carried out in DC systems.

\subsection{Main concepts of the optimization of the PSD methodology}

In this section the methodology carried out until now and published in papers that were mentioned previously is treated $[1,4]$.

\subsubsection{Zonal discretization and weighting elements}

The discretization of the layout of the railway line is a very important concept because it handles the distances like a bidimensional space and permits the critical zones stay along the line. This reason is one of the highlights of the methodology.

Initial step must be to associate the installation zones to the initial discretization. The critical point is related to the assurance to install a traction substation inside each installation zone.

The second step has a relationship with other important concept in this methodology. In railway electrical dimensioning design is mandatory taking into account several impact factors, which must be critical in terms of evaluating budget and time in construction and maintaining the project. In the recent years in CITEF, these critical factors have been linked with critical zones to study in this methodology:

- Environmentally protected zones

- Zones for maintenance of the railway infrastructure

- Zones related to the evaluation of difficulty of connection between general electric grid and traction substation

The ability of the system depends on the action of discretizing the map belonging to the initial route of the circulations of the trains. During this initial step, the length of the line is analysed. This length will be divided into zones in such a way that one traction substation will be able to be installed in each of this zone. In fact, this will be critical in the process of determining the positions of substations and if the participation of them is necessary in this zone or not.

Determining the cost or weight of each element and zone involved in each project is important to know if these costs are real or weighted.

\subsubsection{Electrical validation of PSDs}

The most important and critical thing to do would be finding a way to test a PSD but not the entire operation plan. The final Pareto Front filled by the genetic algorithm must be composed by individuals with good fitness, even global optimum. But obviously, these individuals must be validated in terms of electrical criteria. The process must be run into a finite and efficient computational time. 
Hence while searching about possibilities, one can realize the first approximation to the problem was working with a pair of ways during the simulation. The first way was to attain the calculation of the voltage drops on each cycle. Second alternative was the calculation of the power supply from the traction substations, again on each cycle of the simulation. But both have a critical problem. The final results are highly connected with the calculation about the power supply system. This means that each scenario will have its own final results for both, and obviously that avoids a permanent and homogeneous concept to compare and validate any power supply scenario.

The solution embarked in this methodology is linked with the idea of maximum power demanded peak. This allows a steady-state parameter for any PSD, so this is hardly connected only with the mechanical part of the infrastructure. The initial simulation usually has the higher power demanded peaks at any snapshot belonging to this simulation. In cases of fail, simple or complete in any traction substation, is got the time when demanded power is higher, just affecting to traction substations, even to their rectifiers.

\subsubsection{Genetic algorithm AMGA-II}

The final consequences of analysing the problem were the need to integrate a powerful optimization algorithm, which was able to work with a multi-objective problem, nonanalytical theory model and hardly non-linear model. The choice was AMGA-II. This genetic algorithm has a good computational time and is a raising evolution for a later algorithm, and of course a knowing process about its main configuration parameters has been necessary. These parameters must be met during each working process of the methodology, which creates a conjunction between the other parts of it and the heuristical work proposed for AMGA-II. Finally a set of Pareto optimal individuals is got and there will be the goal of AMGA-II.

\subsubsection{Objective functions and restrictions}

The objectives are divided into installation costs and operation costs. The first one combines the environmental and general electric grid connection areas with basic elements; the operational costs include the maintenance costs with losses in energy.

\subsection{Integrating LCC versus direct and indirect costs and energy losses}

The new approach to evaluate the PSD has been enhanced to adapt the LCC in maintenance, critical elements and interaction between energy losses. For this purpose, changes must be developed in the theoretical model represented by the objective functions in the evaluation of the genetic algorithm. In the following section innovations depending on both the objective functions are explained.

\subsubsection{Including changes in installation objective function}

To know the past objective function, the element costs and the impact on environmental and maintenance zones are important. New parameters and other calculation factors are also important in this task.

In an interesting paper referenced before (Chuang et al. [13]), the authors have included some equations in their model to add the influence of costs and inflation/interest rates [15] during life cycle. In this article, a first approximation taking this main idea has been developed. 
To add the impact of the LCCs of the catenary and traction substations, determined by the designer:

- Overhead contact line direct costs

$$
\text { CostOhl }=\sum_{o=1}^{\text {nohl }} \frac{\text { budget }_{o}}{L C_{o}}+\left(\frac{(1+\sigma)^{L C_{o}}}{(1+\tau)^{L C_{o}}}\right) * \text { budget }_{o}
$$

- Traction substation direct costs

$$
\text { Cost } S s=\sum_{t=1}^{n s s} \frac{\text { budget }_{t}}{L C_{t}}+\left(\frac{(1+\sigma)^{L C_{t}}}{(1+\tau)^{L C_{t}}}\right) * \text { budget }_{t},
$$

where

nohl and $n s s$ are the total numbers for overhead contact lines and traction substations, respectively

budget is for the element, as catenary or traction substation $L C$ is configured life cycle for the elements.

$\sigma$ is expected inflation included in Fisher Equation.

$\tau$ is expected interests costs included in Fisher Equation.

Both equations are a powerful tool to adhere the life cycle of the elements in the calculation of the impact of these elements on the final budget of the PSD.

Once this first step was achieved, the application of the impact of the life cycle inside other important factors for the calculation of installation costs was the next step. In this work the focus on the impact on environmental costs during the years attending to the initial installation was established. After an initial knowledge of the system and a step forward including the planning to add a new measurement for the LCC in environmental zones, the final equation is presented:

$$
\operatorname{CostCE} E_{k}=\operatorname{CostCE} E_{k} \times L C_{t}
$$

where

$\mathrm{LC}_{\mathrm{t}}$ is configured life cycle for traction substation.

Life cycle configured for each traction substations affects directly the environmental costs during the total life of this electrical element.

\subsubsection{Including changes in operation objective function}

Following the idea described in the previous point, the main differences between the later objective functions integrated in the methodology are pointed out.

The reader could examine the papers related with this newly presented work and then realize that in operation costs there are a clear distinction between maintenance impact costs and energy losses. The possibility to get more relevance to one of the calculations is integrated now by means of a probability value.

The equations to operate the calculus of maintenance are very similar to installation costs introduced in the previous section. The difference is the concept of maintenance costs of elements. This is the preconfigured value the designer must include to match the overhead contact line and traction substation with the expected cost in maintenance for a single year. Furthermore 
the equations are the same except changing budget ${ }_{0}$ to budget_ $\mathrm{m}_{0}$. Another relevant matter is the incorporation of the impact of the life cycle on the calculation of the maintenance zone, which finally is similar to the environmental zone changes explained earlier.

In energy losses calculation the impact of life cycle of the traction substation versus energy losses calculated in the simulation is included. That defines a new relationship between the losses calculated in one single cycle of time and an extrapolation of the life cycle of the traction substation:

$$
\text { Losses }=\sum_{t}^{n s u b s t}\left(\sum_{r=1}^{n s u b s t} S s u b s t_{r}-\sum_{u=1}^{\text {trains }} P e t_{u}\right) * \frac{L C_{t}}{\text { porc }_{-} L C}
$$

where

porc_LC is the total life cycle years calculated for the set of traction substations in the power supply system analysed.

So finally

$$
f_{2}(x)=\text { Factor }_{m} * \sum_{v=1}^{n s u b s t}\left(\text { CostCM }_{v}\right)+\text { Factor }_{l} \alpha * \text { Losses }
$$

where

Factor $_{m}$ is the value in $\%$ assigned to maintenance in front of Factor $_{l}$ that represents the $\%$ assigned to losses calculated.

The rest of the variables are explained in the papers referenced later.

\section{OUTCOMES}

Applying a genetic algorithm to a complex, non-linear and non-analytic model is important in the set of tests. This set must validate the methodology in terms of searching an optimum of budget and is electrically convenient for the railway infrastructure. Here is shown a specific test using our methodology. This test is based on a real railway project, and its main characteristics are as follows:

- Geometry and elevation view: Double track along the whole route and 13 stations. Speed restrictions have also been taken into account (Fig. 1).

- Rolling stock: A train with 6 cars, maximum speed $80 \mathrm{~km} / \mathrm{h}$, maximum service acceleration $1 \mathrm{~m} / \mathrm{s}^{2}$, maximum service deceleration $0.9 \mathrm{~m} / \mathrm{s}^{2}$.

- Signalling: The planned signalling system for this line was CBTC.

- Electrical scenario: The line is direct current at 1,500 V. Two types of overhead line systems have been chosen. Seven traction substations are considered to install on initial design.

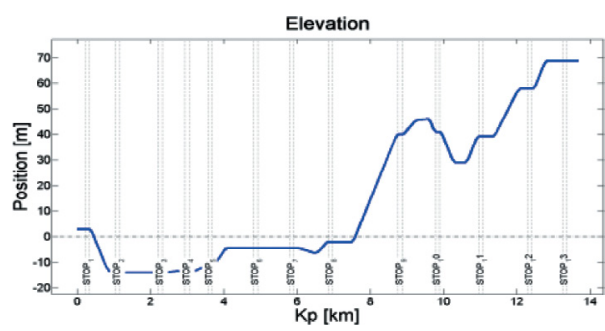

Figure 1: Elevation of the line. 
- Trains with a 90s of headway. Stopping times in stations are 15-20 seconds, depending on the station stop. In case of any rectifier fail, the operation will be degraded as well.

Finally, the main characteristics of the machine used for this optimization process are i5-2400 3,1 GHz 4Gb RAM.

Once the project has been configured in the methodology, and the main parameters belonging to the genetic algorithm, the next is to test the system. Several tests have been launched with differences in some parameters of configuration (Table 1). Next figures are the Pareto Front belonging to the three main tests.

Figure 2 shows the three more representative tests. The results brought by the tests are very interesting in the way to get the key to understand the performance of new skills. Obviously the tests have similar specific data. These similarities have given the opportunity to get clear
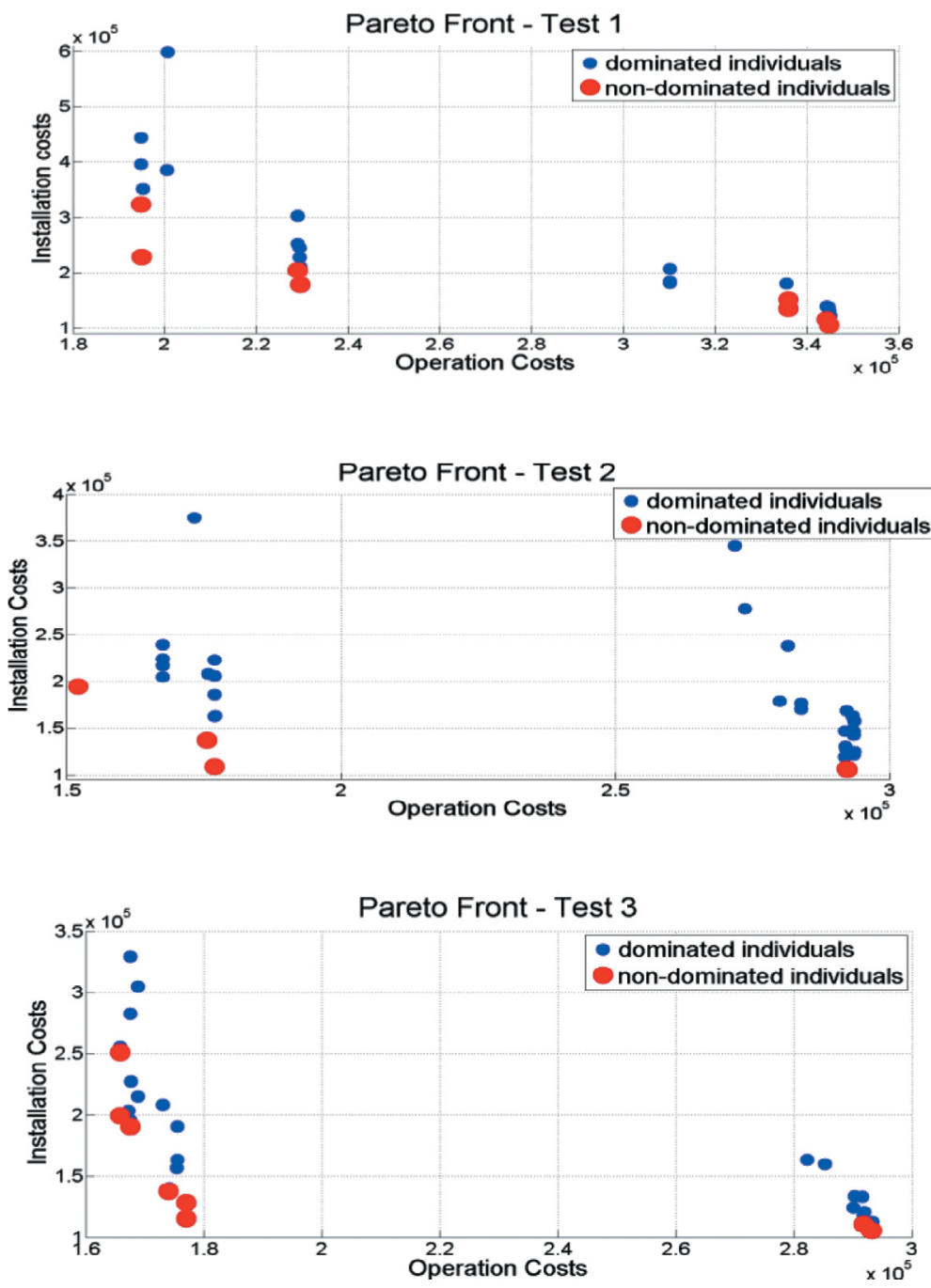

Figure 2: Pareto Front in three different cases. 
Table 1: Configuration of main parameters related to calculation of LCC.

\begin{tabular}{lccc}
\hline & Test 1 (cost/LC/CM) & Test 2 (cost/LC/CM) & Test 3 (cost/LC/CM) \\
\hline Substation 1 & $1 \mathrm{E} 5 / 5 / 40$ & $1 \mathrm{E} 5 / 45 / 4$ & $1 \mathrm{E} 5 / 45 / 4$ \\
Substation 2 & $4 \mathrm{E} 5 / 15 / 6$ & $4 \mathrm{E} 5 / 45 / 6$ & $4 \mathrm{E} 5 / 45 / 6$ \\
Substation 3 & $1 \mathrm{E} 5 / 10 / 5$ & $1 \mathrm{E} 5 / 40 / 5$ & $1 \mathrm{E} 5 / 40 / 5$ \\
Substation 4 & $4 \mathrm{E} 5 / 20 / 30$ & $4 \mathrm{E} 5 / 50 / 3$ & $4 \mathrm{E} 5 / 50 / 3$ \\
Substation 5 & $7 \mathrm{E} 5 / 80 / 3$ & $2 \mathrm{E} 4 / 50 / 5$ & $2 \mathrm{E} 6 / 20 / 25$ \\
Substation 6 & $4 \mathrm{E} 5 / 20 / 20$ & $2.4 \mathrm{E} 4 / 50 / 25$ & $2.4 \mathrm{E} 6 / 20 / 2$ \\
Substation 7 & $4 \mathrm{E} 5 / 10 / 5$ & $4 \mathrm{E} 5 / 40 / 5$ & $4 \mathrm{E} 5 / 40 / 5$ \\
Maintenance 1 & 2000 & 2000 & 2000 \\
Maintenance 2 & 500 & 500 & 500 \\
Maintenance 3 & 20 & 3000 & 3000 \\
Maintenance 4 & 200 & 3200 & 3200 \\
Environmental 1 & 2000 & 2000 & 2000 \\
Environmental 2 & 200 & 200 & 200 \\
Environmental 3 & 20 & 320 & 320 \\
Environmental 4 & 200 & 3200 & 3200 \\
\hline
\end{tabular}

the differences when the new parameters are changed. The AMGA-II has been parameterized with 120 final evaluations and 25 desired solutions. Mutation probability is 0.2 and crossing probability 0.7 . The threshold for removing traction substation is 0.28 .

Focusing on the three final Pareto Fronts, two very clear behaviours were found. On the one hand, independently the configuration AMGA-II tries to locate two different final designs. There is a better side in terms of installation and another part is better in operation terms. The reason is related to the relative location of traction substation 5. In any case, the tests are useful to remove this traction substation and that allows considerable saving of money in global budget. On the other hand, obviously, the algorithm takes into account the energy losses and maintenance costs and awards the possibility to keep the substation 5. Due to that the energy losses are less, even with a relative low life cycle. This part belongs to the best part of individuals bearing in mind the installation costs. Moreover, the factors of maintenance and energy losses integrated in operation objective function (explained in Section 2) have their influence in the final results. For these tests, the values have been 0.7 for Factor $_{l}$, and naturally, 0.3 for Factor $_{m}$. Hence the energy losses gain more relevance inside the operation costs.

One of the choices represented in final Pareto Fronts has been collected to analyse the electric restrictions, such as correct power supply to the demand of trains and avoiding critical voltages. The final example is on the Pareto Front of case 2. It is examining a proposed scenario for the best fitness in terms of installation costs, that is, in net costs of elements involved in this PSD and analysing the impact on environmental zones and LCC for these elements. The main characteristic is the choice of the second type of catenary for the railway line and the removing of the sixth traction substation. The reallocation of the rest of substation is another highlight.

Observing Figs. 3 and 4, it is interesting to conclude that even in the worst situations, when substation 7 or 5 falls, the power system is able to avoid the limits of the normative in minimum voltages in catenary and maximum voltages in return earth rail. Despite the voltage rise till $152 \mathrm{Vcc}$ in situations like permanent regime, $360 \mathrm{~s}$ and $3600 \mathrm{~s}$, the voltage is under limits. 


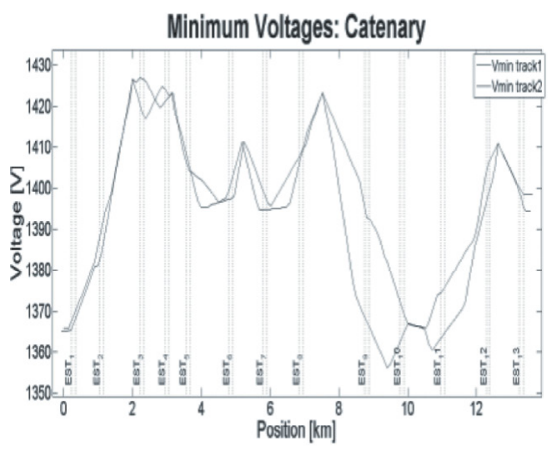

(a)

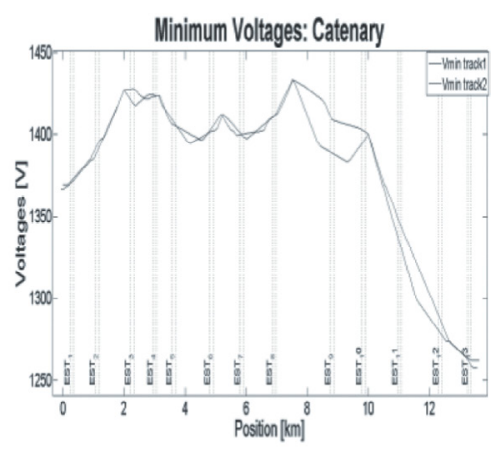

(b)

Figure 3: Minimum voltages in catenary in cases (a) degraded in ss 5 and (b) degraded in ss 7.

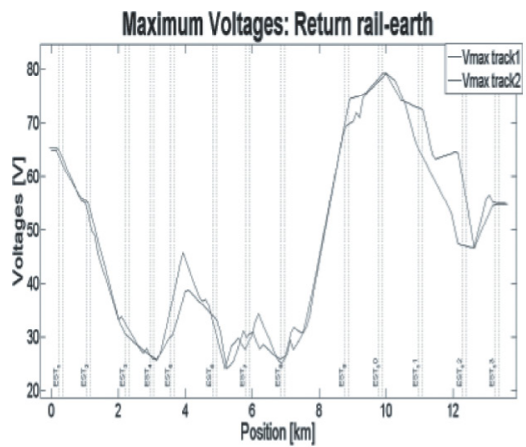

(a)

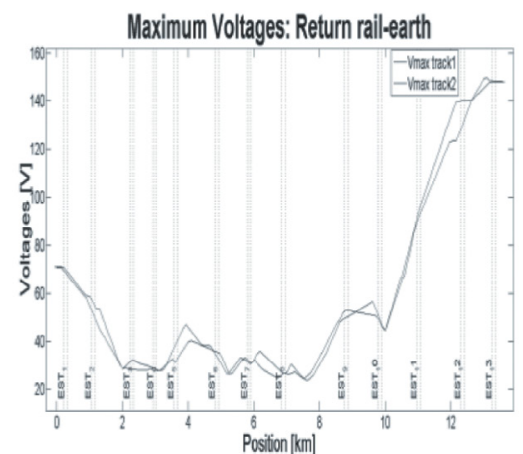

(b)

Figure 4: Maximum return voltages between rail and earth in cases (a) degraded in ss 5 and (b) degraded in ss 7 .

Focusing on the allocation and therefore the subrogation to LCC and environmental costs is important to say that the methodology helps the optimization to remove the substation in worst zone, in terms of environmental costs. On the other hand if it sticks out the difference between LCC in substation 4 till 7, it is important to note that the methodology has tried to remove substation 5 or 6 , discarding from the beginning the others, due to the life cycle, 40 versus 20 .

\section{CONCLUSIONS}

The satisfactory results obtained during the optimization process in the past using our methodology have not been a barrier to try to go a step forward. In this article an improvement that introduces the concepts of LCC joined with energy losses, main elements (traction substation and overhead contact line) and maintenance and environmental zones has been presented. Once the modifications have affected directly the objective functions, on the core of the genetic algorithm, then the need is to test deeply the new skills. In this article one of the tests has been detailed and the effectiveness of the optimization methodology in terms of proposing a set of final best choices has been described. This set has considered budget conditions and electrical restrictions, and it is proved that now we are able to work towards PSD in terms 
of LCC linked with direct and indirect costs, taking into account the energy losses during the life cycle of elements, and depending on the relevance in this matter, we are able to define a better solution as well. Next ways of research must be directed to enhance this technique and to include some studies of energy regeneration during optimization process.

\section{REFERENCES}

[1] Soler, M., López, J., Mera, J. M. \& Tapia, S., Expert system using multi-objective optimization of the direct current railway power supply system. Transport, pp. 1-12, 2015.

[2] Soler, M., López , J. \& Mera, J. M., Simulation system for the optimization of a block distribution under the ERTMS-1 signalling system, de Computer in Railways XII, WIT Press, pp. 61-73, 2012.

[3] Deb, K., Amnit , P. \& Sameer, A., A fast and elitist multiobjective genetic algortihm NSGA-II. IEEE Transactions on Evolutionary Computation, 6(2), pp. 182-197, 2002. DOI: $10.1109 / 4235.996017$.

[4] Soler, M., López, J., Mera , J.M. \& Maroto, J., Methrodology for Multiobjective Optimization of the AC Railway Power Supply System. IEEE Transactions on Intelligent Transportation Systems, 15(5), pp. 2531-2542, 2015. DOI: 10.1109/TITS.2015.2412460.

[5] Tiwari, S., Fadel, G. \& Deb, K., AMGA2: improving the performance of the archivebased micro-genetic algorithm for multi-objective optimization. Engineering Optimization, 43(4), pp. 377-401, 2011. DOI: 10.1080/0305215X.2010.491549.

[6] Rondón, I., Calache ,V. \& Rojas, F., Metodología para estimar la vida útil del autotransformador AT-4, 700 MVA de la subestación Guayana 'B' debido a sobrecargas. Universidad Ciencia y Tecnología, 17(64), 2014.

[7] Chester, M. \& Horvarth, A., Life-cycle assessment of high speed rail: the case of California. Environmental Research Letters, 5(1), 2010. DOI: 10.1088/1748-9326/5/1/014003.

[8] Abbes, D., Martinez ,A. \& Champenois, G., Life cycle cost, embodied energy and loss of power supply probability for the optimal design of hybrid systems. Mathematics and Computers in Simulation, 98, pp. 46-62, 2014. DOI: 10.1016/j.matcom.2013.05.004.

[9] Cerri, D., Taisch, M. \& Terzi, S., Multi-objective Optimization of Product Life-Cycle Costs and Environmental Impacts. Advances in Production Management Systems. Competitive Manufacturing for Innovative Products and Services, pp. 391-396, 2012.

[10] Salim, V. \& Xiaoqiang, C., A genetic algorithm for railway scheduling with environmental considerations. Environmental Modelling and Software, 12(4), pp. 301-309, 1997. DOI: 10.1016/S1364-8152(97)00026-1.

[11] Baumgartner, J.P., Prices and Costs in the Railway Sector, Zurich: Institut des Transport et de planification, 2001.

[12] Açıkbaş ,S., \& Turan Söylemez, M., Energy loss comparison between 750 VDC and 1500 VDC power supply systems using rail power simulation, de Computers in Railways IX, WIT Press, pp. 951-960, 2004.

[13] Chuang, H., Chen, C., Lin, C., Chen, Y. \& Ho, C., Optimal Expansion Planning of Traction Substations for an Electrified Mass Rapid Transit System. de International Conference on Power System Technology, pp. 1-7, 2006.

[14] Hinow ,M. \& Mevissen, M., Substation maintenance strategy adaptation for life-cycle cost reduction using genetic algorithm. IEEE Transactions on Power Delivery, 26(1), pp. 197-204, 2011. DOI: 10.1109/TPWRD.2010.2065247.

[15] Fisher, I., The Theory of Interest, New York: The Macmillan Company, 1930. 